\title{
Imagens e estereótipos do Brasil em reportagens de correspondentes internacionais ${ }^{1}$
}

\author{
Ivan Paganotti ${ }^{2}$ (USP)
}

\section{Resumo}

$\mathrm{O}$ artigo trata da cobertura dos correspondentes internacionais sobre o Brasil. A partir da análise dos textos publicados entre 2002 e 2005, o estudo traça um perfil das imagens e estereótipos mais utilizados para representar uma identidade nacional. A pesquisa foca os textos publicados em The New York Times (EUA), El Mundo (Espanha), Diário de Notícias (Portugal), The Guardian e The Observer (ambos da Inglaterra), Página/12 e El Clarín (ambos da Argentina). Por meio da análise de discurso crítica, a avaliação quantitativa e qualitativa apontou as estratégias utilizadas pelos correspondentes para construir as imagens coletivas referentes ao país. A temática e os processos de estereotipia predominantes foram organizados em quatro grupos de representações de diferentes "Brasis": um "verde", sobre a preservação e a depredação ambiental; outro "de lama", corrupto e pobre; um "sangrento", sobre a violência e as drogas; e outro "de plástico", rico, carnavalesco e à venda para os turistas.

Palavras-chaves: Correspondentes internacionais; Brasil; identidade nacional; estereótipos; análise crítica de discurso.

\begin{abstract}
The paper deals with the coverage given to Brazil by international correspondents. Based on an analysis of articles published between 2002 and 2005 , the study traces a profile of the most common stereotypes representing national identity. The research focuses on articles published in The New York Times (USA), El Mundo (Spain), Diário de Notícias (Portugal), The Guardian and The Observer (both from Britain), and Página/12 and El Clarín (both from Argentina). A critical discourse analysis and quantitative and qualitative evaluation indicated the strategies used by the correspondents to build the collective images referring to the nation. The predominant stereotypical subjects and processes were organized into four groups representing different "Brazils":
\end{abstract}


"green", about environmental protection and devastation; "mud", about corruption and poverty; "blood", about violence and drugs; and "plastic", about wealth, Carnival, and being up for sale to tourists.

Keywords: Foreign correspondents; Brazil; national identity; stereotypes; critical discourse analysis.

\section{Introdução}

Os principais diários internacionais apresentam o Brasil como uma nação assombrosa, oscilando entre paraíso tropical e inferno dantesco (BURKE, 2006). Sérgio Barreto Motta, correspondente do jornal português Diário de Notícias define a atmosfera carioca dos anos 1950, numa metonímia involuntária da imagem do país inteiro: "uma aura de cidade de diversões, uma certa libertinagem, muito carnaval e um pouco de pecado" (MOTTA, 2004). "Diversões", "libertinagem", "carnaval" e "pecado" são imagens estereotipadas freqüentemente relacionadas com $\circ$ Brasil em diversas mídias, como a literatura (GOLDSTEIN, 2003) e o cinema (AMANCIO, 2000).

Diferentes jornais internacionais também constroem uma imagem do país nas suas reportagens sobre desmatamentos na Amazônia, violência nas favelas, fome e seca no nordeste ou sobre a corrupção generalizada. Para sistematizar, analisar e até mesmo desconstruir essas concepções do Brasil, este estudo analisou a produção dos correspondentes de jornais estrangeiros quanto à repetição ou transformação de imagens, pré-conceitos e estereótipos sobre o país. Este artigo baseia-se na coleta, organização, análise e interpretação dos textos publicados entre 2002-2005 em diários americanos, ingleses, espanhóis, portugueses e argentinos.

Desde o descobrimento, as impressões estrangeiras são uma das maiores fontes da nossa identidade nacional (PRATT, 1999). Os primeiros relatos que divulgaram a existência do Brasil na Europa foram apresentados por viajantes estrangeiros como o italiano Américo Vespúcio e o alemão Hans Staden (FERRAZ, 2002: 7) ou nas cartas de jesuítas portugueses que davam notícias do processo de colonização do país (HUE, 2006: 16-8).

Atualmente, Herman e McChesney definem os meios de comunicação globais como verdadeiros "missionários do capitalismo corporativo" (HERMAN 
\& MCCHESNEY, 1998: 10). O evangelho pregado por esses novos jesuítas não só defende os princípios da abertura das economias de mercado, mas também são eles mesmos definidos como grandes conglomerados multinacionais, que lucram com a venda da notícia como mercadoria (HABERMAS, 2003: 35). Nesse contexto, as matérias dos correspondentes internacionais atuam como os novos "relatos de viagem", levando as notícias do Brasil para os públicos estrangeiros.

Em 2005, eram três centenas de correspondentes internacionais no país, de mais de noventa veículos (CORTEZ, 2005). Concentrados no Rio, em São Paulo e em Brasília (ibid.), a maioria dos jornalistas é composta por americanos, ingleses e alemães (PINHEIRO, 2002). Estimativas de 2002 apontavam que publicam em média 18 mil reportagens por ano $-60 \%$ delas sobre a economia (ibid.). É um fluxo gigantesco de informação e interpretação de fatos, que não pode ser desconsiderado pelos estudos de comunicação. Analisar esses textos é destrinchar os "olhares estrangeiros" que constroem as visões dos seus compatriotas formadores de opinião, "uma elite, cuja opinião ajudam a formar e, por sua vez, são influenciados por ela" (MOLINA apud BERABA, 2005).

O objetivo deste artigo é tratar dessas visões internacionais sobre o Brasil e das estratégias para a construção, reprodução e transformação de estereótipos e pré-concepções sobre o país. Segundo Hall, o imaginário sobre uma identidade cultural nacional é construído com base na "narrativa da nação" (HALL, 2001: 52). Para "imaginar uma cultura" é necessário construir narrativas sobre a representação dessas identidades como as tradições e os mitos fundacionais - os founding fathers e o "destino manifesto" norte-americanos ou a tríade "indígenas, europeus e negros" da formação do povo brasileiro.

Para Burke, as representações na mídia cinematográfica e jornalística (tanto nacionais quanto estrangeiras) podem ser divididas entre visões do Brasil como "paraíso" - seja turístico, sexual, dos criminosos em fuga ou da "democracia racial" - ou "inferno" - da corrupção e, principalmente, da violência (BURKE, 2006).

Os textos dos correspondentes internacionais também participam na construção de um imaginário coletivo estrangeiro sobre os temas e os locais de que tratam (DOTA, 2005: 1). Esse processo envolve a explicação e 
simplificação de conceitos complexos - como a definição do perfil do brasileiro ou dos temas característicos do país - por meio de estratégias de representação baseadas em conhecimentos, pré-concepções, pressupostos e estereótipos comuns entre os jornalistas e seu público.

Lippman define pela primeira vez o conceito de estereótipos no livro Public Opinion ao designar as "imagens em nossa cabeça" que representam a percepção de certas facetas da realidade (LIPPMAN apud MAISONNEUVE, 1977: 114). Segundo Maisonneuve, os estereótipos são criados para agregar, simplificar e categorizar o mundo. Seu mecanismo é inerente à própria compreensão humana, que procura diferenciar, generalizar e esquematizar para conseguir absorver informações (MAISONNEUVE, op. cit: 118). Mas o autor frisa que "a mira dos estereótipos não é a busca de uma verdade cientifica, mas, antes, a de uma eficácia pragmática, ou ideológica" (ibid.: 122). Por basearem-se em relações afetivas em detrimento de observações empíricas, os estereótipos dizem menos sobre a realidade do que é retratado e mais sobre como (e por que) é retratado.

De forma mais ampla, podemos definir como "pacote cognitivo" a somatória de conceitos, visões, impressões, pressupostos e estereótipos que membros de um mesmo público compartilham e são capazes de, em menor ou maior grau, identificar ou reproduzir, o que é essencial para a existência da comunicação. Os estereótipos diferenciam-se do resto do "pacote cognitivo" pela utilização de processos de seleção e acentuação de características para representar conceitos, grupos ou práticas que estão relacionados socialmente com o coletivo que os criou ou sustenta.

É nessa esfera de reprodução de estereótipos que os textos dos correspondentes internacionais foram avaliados. Nem sempre é possível para os correspondentes contextualizar ou aprofundadas seus temas - seja por falta de tempo na produção das reportagens ou por falta de espaço para expô-las apropriadamente para seu público. Nesses casos, Hannerz alerta para o risco de simplificações, pré-concepções, modelos interpretativos pré-estabelecidos e até mesmo clichês: "Se você cai como um pára-quedista no meio de uma zona de batalha [na África] com pouco preparo, o 'kit de ferramentas' com as pressuposições primordialistas e os clichês talvez seja conveniente demais" (HANNERZ, 2004: 123). 
A praticidade e a simplicidade dos clichês para a compreensão e a divulgação superficial de informações podem parecer vantajosas, mas são extremamente perniciosas. Maisonneuve aponta que "o próprio da estereotipia é ser grosseira, rígida, brutal e repousar numa espécie de essencialismo simplista" (MAISONNEUVE, op. cit: 118). Por isso, não é possível ignorar as armadilhas dos estereótipos: o preconceito, a fixação, a superficialidade, o reducionismo, a caricatura, o exagero e a repetição.

Talvez o lado mais evidentemente negativo e simplório dos estereótipos possa ser visualizado no cinema. Amancio aponta que algumas das imagens representadas no cinema estão enraizadas no imaginário europeu e americano devido às pinturas de Franz Post e Albert Eckhout, como o "sol, mar, praias desertas, cobertas de palmeiras (...), um lugar permanentemente em festa" (AMANCIO, 2000: 43). O autor lista alguns motivos do repertório que os filmes comumente associam ao Brasil, como o futebol, o carnaval, o samba, a floresta, o mulato, o papagaio, as drogas, a violência, a impunidade e outros problemas sociais (ibid.: 116-25). Excetuando-se a ave ícone nacional, esses temas são freqüentes também na cobertura que os correspondentes fazem do Brasil.

\section{Método}

Foram analisados textos publicados por correspondentes em jornais internacionais entre 2002 e 2005. Buscando uma amplitude dentro da amostra da pesquisa, foram escolhidos periódicos de idiomas, nacionalidades, públicos e posicionamentos diversos: The New York Times (EUA); El Mundo (Espanha); Diário de Notícias (Portugal); The Guardian e The Observer (ambos da Inglaterra); Página/12 e El Clarín (ambos da Argentina). As reportagens foram obtidas no site dessas publicações por meio de busca por autor, com base nos nomes dos correspondentes no Brasil.

Os 1.244 textos selecionados permitem um trabalho estatístico representativo: estimativas apontam que os correspondentes publicam em média 18 mil textos sobre o Brasil a cada ano (PINHEIRO, 2002), o que significa que foram analisados $1,7 \%$ dos textos publicados nos quatro anos focados na pesquisa. 
A leitura dos textos seguiu os princípios da análise crítica do discurso, definida por Fairclough como o exame das conexões implícitas entre as características textuais e os processos sociais (FAIRCLOUGH, 1997: 97), avaliando as inter-relações entre linguagem, poder e ideologia (idem, 1992: 5).

Fairclough aponta que as pressuposições, os estereótipos e os sensoscomuns dissimulam e reforçam ideologias (ibid.: 92). Os estereótipos foram definidos entre as imagens comumente atreladas ao Brasil (mencionadas na Introdução), considerando as representações mais freqüentes na amostra. Assim, uma reportagem que menciona que "nas favelas, com armas pesadas e muita violência, os traficantes controlam os acessos e as vidas das pessoas, perante a impotência da polícia e a omissão dos serviços públicos de ordem social" (MOTTA, 30/12/2004) reforça tanto a imagem negativa das favelas atrelada ao "tráfico de drogas" - quanto o pressuposto de que "criminosos dominam o poder" nesses bairros.

Mas mesmo os pressupostos já cristalizados socialmente podem ser contestados (FAIRCLOUGH, 1992: 154). Dessa forma, esta pesquisa identificou se os textos procuravam reproduzir (por meio da repetição) ou transformar (pela contestação, discussão ou até mesmo negação) os pressupostos e estereótipos apresentados. Para isso, foi avaliado o efeito cumulativo ou reprodutivo desses instrumentos de representação simplificada, distinguindo estratégias normativas (de reprodução) ou criativas (de transformação). Segundo a hipótese de Fairclough, se as manifestações criativas e adaptativas forem mantidas em longo prazo, elas podem também alterar permanentemente as próprias imagens, pressupostos ou estereótipos que a opinião pública tem sobre certos temas (idem, 1992: 165). É esse também 0 interesse desta linha de pesquisa: mostrar quais são os primeiros passos para desconstruir ou reformar a imagem que os estrangeiros têm sobre o Brasil.

\section{Resultados e discussão}

A leitura dos 1.244 textos publicados pelos sete veículos selecionados demonstrou que é possível agrupar as representações do Brasil em pequenos 
grupos temáticos estereotipados. Quatro representações de "Brasis" diferentes foram delimitadas nos seguintes blocos de estereótipos:

Brasil "verde": Um grupo de estereótipos tão antigo quanto os relatos dos descobridores foca a exaltação da beleza natural da paisagem, da flora e da fauna brasileiras. Durante a colonização, tratava das possibilidades de exploração das terras, como os primeiros relatos sobre o pau-brasil e o uso das terras para a agricultura (FERRAZ, 2002: 10), mas esse enfoque foi por muito tempo deixado num segundo plano - talvez retomando sua força com a discussão atual sobre o agronegócio e os biocombustíveis. A maioria das matérias desse grupo aborda a ameaça ambiental e os desafios ecológicos da preservação das florestas e dos povos que dela vivem.

Brasil "de lama": Nesse agrupamento estão textos sobre a (corrupção) política, o subdesenvolvimento e a pobreza endêmica - freqüentemente interrelacionados ou acompanhados pela "violência". Como definido por Hamid Mowlana, "a corrupção no terceiro mundo é representada como sistemática, assim como as violações de direitos humanos" (MOWLANA, 1986: 49-50).

Brasil "de sangue": O principal enfoque negativo é o da violência, que engloba o tráfico de drogas, e causa um cenário de insegurança generalizada. Essa violência comumente é justificada por fatores estruturais, como a omissão I corrupção do governo, a pobreza e a exclusão social (como citados na representação do "Brasil de lama"). A representação de um país "sangrento" também evidencia que ninguém está seguro, pois a violência é aberta e onipresente (ibid.: 50).

Brasil "de plástico": No lado mais otimista e laudatório das representações, está uma visão excessivamente publicitária do país: é a nação das festividades carnavalescas, da liberdade sexual (seja qual for a orientação), dos negócios, da alta sociedade e seus caprichos. Freqüentemente trata da cultura como um produto para exportação - ou aluguel turístico. Extremo oposto das outras duas representações anteriores ("de lama" e "sangrento"), também envolve os mitos do crescimento econômico e do desenvolvimento tecnológico que colocariam o país entre uma das nações "do futuro", incluindo as reportagens sobre empresas brasileiras "bemsucedidas". 
A Tabela 1 apresenta os principais estereótipos, aglutinados nesses quatro grupos temáticos, segundo sua reprodução ou transformação, e suas freqüências nos textos dos correspondentes internacionais analisados.

Tabela 1 - Estereótipos: Reprodução, Transformação e Freqüência nos textos - 2002-2005.

\begin{tabular}{|c|c|c|c|c|c|}
\hline Brasil & Estereótipos & Reproduz & Transforma & Total & Freqüência* \\
\hline \multirow[b]{4}{*}{ Sangue } & Tráfico de drogas & 99 & 3 & 102 & $8,2 \%$ \\
\hline & Insegurança & 69 & 0 & 69 & $5,5 \%$ \\
\hline & Crime domina o País & 34 & 2 & 36 & $2,9 \%$ \\
\hline & Convulsão social & 26 & 1 & 27 & $2,2 \%$ \\
\hline \multicolumn{2}{|c|}{ Sangue - Total } & 228 & 6 & 234 & ------- \\
\hline \multirow[b]{9}{*}{ Lama } & Corrupção generalizada & 59 & 2 & 61 & $4,9 \%$ \\
\hline & Discriminação & 33 & 14 & 47 & $3,8 \%$ \\
\hline & Pobreza & 26 & 9 & 35 & $2,8 \%$ \\
\hline & Impunidade & 24 & 2 & 26 & $2,1 \%$ \\
\hline & Coronelismo & 10 & 4 & 14 & $1,1 \%$ \\
\hline & Ignorância & 6 & 2 & 8 & $0,6 \%$ \\
\hline & Incompetência & 7 & 0 & 7 & $0,6 \%$ \\
\hline & Indiferença política & 3 & 3 & 6 & $0,5 \%$ \\
\hline & Jeitinho brasileiro & 4 & 0 & 4 & $0,3 \%$ \\
\hline \multicolumn{2}{|c|}{ Lama - Total } & 172 & 36 & 208 & ------- \\
\hline \multirow[t]{7}{*}{ 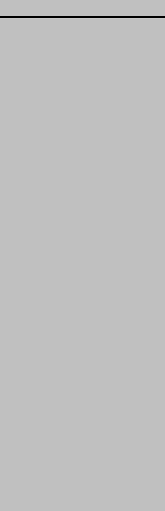 } & Depredação ambiental & 31 & 12 & 43 & $3,5 \%$ \\
\hline & País exótico & 24 & 1 & 25 & $2,0 \%$ \\
\hline & Falta de soberania na & & & & \\
\hline & Amazônia & 12 & 5 & 17 & $1,4 \%$ \\
\hline & Terra sem lei & 16 & 0 & 16 & $1,3 \%$ \\
\hline & Função ecológica da & & & & \\
\hline & Amazônia & 9 & 3 & 12 & $1,0 \%$ \\
\hline Verde & Celeiro do mundo & 6 & 2 & 8 & $0,6 \%$ \\
\hline \multicolumn{2}{|c|}{ Verde - Total } & 98 & 23 & 121 & ---.--- \\
\hline \multirow[t]{2}{*}{ Plástico } & Sensualidade & 25 & 8 & 33 & $2,7 \%$ \\
\hline & Samba e Carnaval & 16 & 5 & 21 & $1,7 \%$ \\
\hline
\end{tabular}




\begin{tabular}{|l|l|c|c|c|c|}
\hline \multirow{1}{*}{} & Nação do futebol & 16 & 3 & 19 & $1,5 \%$ \\
\cline { 2 - 6 } & Beleza natural & 11 & 1 & 12 & $1,0 \%$ \\
\cline { 2 - 6 } & Noveleiros & 10 & 0 & 10 & $0,8 \%$ \\
\cline { 2 - 6 } & Cordialidade & 8 & 1 & 9 & $0,7 \%$ \\
\cline { 2 - 6 } & Miscigenação & 1 & 8 & 9 & $0,7 \%$ \\
\hline Plástico - Total & $\mathbf{8 7}$ & $\mathbf{2 6}$ & $\mathbf{1 1 3}$ & ------ \\
\hline Total geral & $\mathbf{5 8 5}$ & $\mathbf{9 1}$ & $\mathbf{6 7 6}$ & $\mathbf{3 1 , 2} \%$ \\
\hline Transformação e Reprodução (\%) & $\mathbf{8 6 , 5 \%}$ & $13,5 \%$ & $\mathbf{1 0 0 \%}$ & ------- \\
\hline
\end{tabular}

${ }^{*}$ Freqüência de textos com estereótipos. Um texto pode apresentar mais de um estereótipo.

Como visto na Tabela 1, a freqüência de textos com estereótipos é alta: quase uma em cada três reportagens apresenta essa estrutura representativa simplificadora. Como esperado, a repetição é muito mais comum do que a transformação de estereótipos, pressupostos e pré-concepções. Ainda que o jornal seja um veículo apropriado para valorizar as mudanças, poucos conceitos foram significativamente alterados, como o da discriminação $(29,8 \%$ de transformação), a falta de soberania na Amazônia (29,4\%), o coronelismo $(28,6 \%)$, a depredação ambiental $(27,9 \%)$, a pobreza $(25,7 \%)$, a sensualidade $(24,2 \%)$ e o samba e o carnaval $(23,8 \%)$ - três sobre o Brasil "de lama", dois do "verde", dois do "de plástico" e nenhum do "sangrento". A discriminação contrapõe-se ao único estereótipo com mais transformação do que reprodução: o da miscigenação, com $88,9 \%$ de alterações. Aparentemente, o mito da "democracia racial" é o único já revisto e superado pelos correspondentes internacionais.

Entre os blocos de estereótipos apresentados anteriormente, nota-se uma predominância do Brasil sangrento: as ligações com o tráfico de drogas configuram-se na imagem mais comum entre os textos analisados. Surpreendentemente também é um dos estereótipos com mais baixo índice de transformação, ainda fortemente reproduzido sem alterações ou negações. Outros estereótipos predominantes, como a insegurança, a dominação do crime, a convulsão social e a impunidade, também estão diretamente atrelados 
à visão violenta do país, e apresentam baixíssimos índices de transformação quando não apresentam alteração nenhuma, como é o caso da insegurança.

Em segundo lugar, a representação do Brasil de lama envolve também estereótipos muito repetidos, como a corrupção generalizada, a pobreza e a impunidade. Outros, mais raros, como o coronelismo e a indiferença política, também se enquadram nesse grupo que trata da relação entre 0 subdesenvolvimento e a falência do governo - freqüentemente relacionado a denúncias de corrupção. Assim como a "lama" da corrupção está conectada com a pobreza, também os estereótipos desse grupo aproximam-se da violência do bloco anterior, num ciclo retro-alimentador: o governo omisso e corrupto não cumpre sua função de proteção social; grupos desfavorecidos são "forçados" ou "atraídos" para a violência, que se infiltra no governo e corrompe.

Essa relação pobreza-crime mostra como mesmo a escolha de vocabulário pode influenciar a representação e, conseqüentemente, colaborar com os processos de estereotipia. A frase "com a pobreza e as grandes diferenças sociais, muitos jovens brasileiros são forçados [forced into] (...) a traficar drogas" (PHILLIPS, 30/12/2005.) retira a intencionalidade e, de certa forma, justifica por fatores externos a criminalidade dos que não teriam outra opção para sobreviver. Outro correspondente prefere frisar a responsabilidade e a possibilidade de escolha individual dos que "são atraídos pelo lado podre da sociedade" (MOTTA, 28/11/2004), mas, simultaneamente, segundo o autor, estigmatiza todo um grupo social ao apontar que "é em meio à pobreza que cresce o banditismo" .

Um pouco menos freqüente que 0 anterior, 0 terceiro grupo de estereótipos cria a imagem do Brasil verde, mas que, nos jornais, é predominantemente representada de modo negativo por meio da depredação ambiental e dos menos freqüentes estereótipos sobre a falta de soberania na Amazônia, uma "terra sem lei" vista como "celeiro" para o agronegócio. Ainda assim, a imagem exótica do país e a função ecológica da Amazônia detêm um espaço considerável. Essa é a representação mais antiga do país: se por um lado isso faz com que ela seja uma das mais reconhecidas internacionalmente, por outro, isso diminui seu fator de "novidade", determinante para o noticiário internacional. 
O último grupo apresenta a visão do Brasil de plástico, da alta sociedade e da cultura à venda. É, por isso, o mais próximo do gênero da propaganda. Aglomera as imagens de sensualidade, beleza natural, samba, carnaval, futebol, cordialidade e dramaticidade (das novelas). Nesse grupo, os textos apresentam a exótica arte popular e a beleza natural encaixotadas para a exportação. Também lida com a festividade da música, com sua representação máxima no carnaval, e os novos produtos-conceitos de exportação cultural: as novelas e as cirurgias plásticas. O correspondente do português Diário de Notícias apresenta particular interesse nas novelas: $20,5 \%$ dos seus textos tratam da televisão brasileira, muito acima da média de $1,0 \%$ de todos os jornais analisados.

Surpreendentemente, a preocupação estética com a beleza supera até mesmo os estereótipos sobre as características físicas tradicionais das brasileiras. Retratado com o "reino da cirurgia estética" (LACAVE, 09/03/2003), o país vê o crescimento do "efeito Gisele Bündchen" e da valorização de "pernas longas, cintura estreita e seios volumosos" (LACAVE,16/02/2003) em detrimento de estereótipos anteriores sobre a silhueta natural das brasileiras: "As clínicas especializadas do país não têm uma única vaga para fazer operações e as próteses de silicone escasseiam no mercado. (...) pouco a pouco, as grandes nádegas agitadas ao ritmo de samba estão deixando de ser tão valorizadas quanto uns proeminentes peitos" (ibid.).

\section{Conclusão}

Como explicado na Introdução, os estereótipos são cruciais para a assimilação e reprodução de conceitos complexos, e tem um efeito positivo no noticiário: oferecem um denominador comum a partir dos quais os correspondentes podem construir suas narrativas mais aprofundadas. Mas a armadilha simplificadora dos estereótipos persiste: quando não mais condizem com a situação que representam, eles precisam ser discutidos, transformados e, quando necessário, negados. Considerando que a matéria-prima do jornalismo é a notícia, o fato novo, o diferente e o inusitado, como princípio o correspondente deve procurar focar a transformação, e não somente a reprodução de conceitos - o contrário do constatado neste trabalho. É cômodo 
basear a cobertura em pressupostos, alimentando as pré-concepções com dados, histórias e interpretações que reafirmam o que o público já sabe sobre a realidade ou, no pior cenário, repetir conceitos ideologicamente enviesados que simplesmente não condizem com a verdade.

Alguns dos próprios correspondentes discutem em seus textos sobre os problemas e desafios da utilização de estereótipos. Tornar esse mecanismo mais consciente, tanto por parte do jornalista quanto do leitor, possibilita que seus efeitos negativos sejam também menos perniciosos. Isso é notado quando o correspondente Ramy Wurgaft, do espanhol El Mundo, entrevista o governador do Amazonas, Eduardo Braga (PMDB):

"P: Poderia explicar como é que a soberania do Brasil no Amazonas está em perigo?

R: Agora mesmo, você me perguntava pelas pistas de aterrissagem que funcionam no meio da selva. Supõe-se que também estamos dando cobertura às milícias das Farcs, que fazemos vista grossa com os contrabandistas de madeiras e que nós convertemos os rios em esgotos... O que se insinua de forma bem clara é que os brasileiros só servem para organizar carnavais. Conseqüentemente, seria conveniente, portanto, que um organismo internacional composto por gente civilizada administrasse esse ecossistema essencial para a sobrevivência da Humanidade". (WURGAFT, 25/09/2005)

É necessário também questionar os efeitos da reprodução de estereótipos como o do tráfico de drogas, da falta de soberania amazônica, da insegurança, da corrupção generalizada, da discriminação, da depredação ambiental, do crime que domina o país e da pobreza (os sete estereótipos mais freqüentes nos textos analisados). São imagens que foram criadas e reproduzidas porque simplificam a realidade, mas também porque elas foram escolhidas, por seus autores e por outros antes deles, como representativas. Como apontou o correspondente português Sérgio Barreto Motta em sua "Carta do Rio de Janeiro", antes eram outras as imagens que traduziam o Brasil - imagens mais sensuais, festivas e exóticas, muito menos dramáticas. A superação desses pontos pode ser vista como uma vitória, pois realmente o Brasil não se reduz 
ao carnaval e à chanchada. Mas a conotação extremamente negativa dos novos estereótipos, em comparação com as moralmente dúbias representações anteriores, incomoda mesmo considerando que o jornalismo, por essência, interessa-se mais pelas más notícias.

Não é possível determinar os motivos que levaram às transformações da imagem internacional do Brasil, mas percebe-se, às vezes, alguns dos interesses que regem essas alterações. John Balzar, correspondente do Los Angeles Times na África, incomodava-se por sentir que suas reportagens chocantes e emocionadas sobre guerras, crianças mutiladas e campos de refugiados encaixavam-se como "engrenagens na máquina humanitária mundial" (BALZAR apud HANNERZ, 2004: 46), em que gente civilizada (como na crítica do governador amazonense) administrava, alugava e vendia o sofrimento humano em troca de seus serviços de reparos. Sua advertência sobre os interesses financeiros escondidos na representação dramática da tragédia africana pode apresentar paralelos interessantes em alguns grupos de estereótipos brasileiros.

"A máquina ecológica mundial", mecanismo semelhante ao combate ao drama humanitário africano, preocupa-se com a preservação ambiental das florestas brasileiras - o Brasil verde. A propaganda turística utiliza-se da imagem de um país exótico, naturalmente belo, festivo e sensual - o Brasil de plástico. As empresas de segurança particular e a luta internacional contra o narcotráfico também se interessam pela sensação de insegurança, de dominação do crime - o Brasil sangrento. Não é difícil também imaginar que interesses particulares procurem desmoralizar instituições governamentais ou preservar a imagem e a prática da corrupção, o óleo que lubrifica e faz mover a máquina estatal conforme interesses privados - o Brasil de lama.

Isso não significa que os estereótipos são criados e reproduzidos devido aos seus fins mercantis - mas o efeito, ainda que sem essa intenção, existe. Só resta aos correspondentes visualizar o "maquinário" de interesses em que seus textos se enquadram, para decidir em que sentido girar suas engrenagens. 


\section{Referências bibliográficas}

AMANCIO, Tunico. O Brasil dos gringos: imagens no cinema. Niterói: Intertexto, 2000.

BERABA, Marcelo. "Olhos estrangeiros". Folha de S. Paulo. 11/12/2005.

BOURDIEU, Pierre. “A opinião pública não existe”. In: Questões de sociologia. São Paulo: Marco Zero, 1983. p. 173-182.

BURKE, Peter. "Os turistas aprendizes". Folha de S. Paulo, 17/12/2006. Caderno Mais! p.12.

CORTEZ, Lígia. "Olhai por nós correspondentes". Revista Imprensa (jan-fev/2005).

DOTA, Maria Inez Mateus. "Aspectos políticos do Brasil: uma análise de notícias do New York Times". In: Anais do XXVIII Congresso Brasileiro de Ciências da Comunicação. São Paulo: Intercom, 2005.

FAIRCLOUGH, Norman. Language and power. London; Longman, 1992. . Critical discourse analysis. London: Longman, 1997.

FERRAZ, Oséias Silas. "Nota Preliminar". In: CAMINHA, Pero Vaz de. Carta ao rei Dom Manuel. Belo Horizonte: Crisálida, 2002.

FOUCAULT, Michel. A ordem do discurso. São Paulo: Edições Loyola, 2002. GÂNDAVO, Pero de Magalhães de. A primeira história do Brasil: história da província Santa Cruz a que vulgarmente chamamos Brasil. Rio de Janeiro: Jorge Zahar Editor, 2004.

GOLDSTEIN, Ilana Seltzer. Brasil best seller de Jorge Amado. São Paulo: Editora Senac, 2003

GOMES, Mayra Rodrigues. Poder no jornalismo. São Paulo: Edusp, 2003.

HABERMAS, Jürgen. "Mudança de função política da esfera pública". In: Mudança estrutural da esfera pública. Rio de Janeiro: Tempo Brasileiro, 2003.

HALL, Stuart. A identidade cultural na pós-modernidade. Rio de Janeiro: DP\&A, 2001. HANNERZ, UIf. Foreign news - exploring the world of foreign correspondents. Chicago: The University of Chicago Press, 2004.

HERMAN, Edward S.; MCCHESNEY, Robert W. "The rise of global media". In: The global media - the new missionaries of corporate capitalism. Nova Déli: Madhyam Books, 1998.

HUE, Sheila Moura. Primeiras cartas do Brasil [1551-1555]. Rio de Janeiro: Jorge Zahar Editor, 2006. 
LACAVE, Emilio, "El primer dinero, para operarse", El Mundo, 09/03/2003.

LACAVE, Emilio "La silicona se agota en brasil", El Mundo, 16/02/2003.

MAISONNEUVE, Jean. "Opiniões e estereótipos”. In: Introdução à psicossociologia. São Paulo: Edusp, 1977. p. 110-125.

MOTTA, Sérgio Barreto, "Uma carta do Rio de Janeiro", Diário de Notícias, 28/11/2004.

MOTTA, Sérgio Barreto, "Polícia cerca favelas do Rio de Janeiro", Diário de Notícias, 30/12/2004

MOWLANA, Hamid. Global information and world communication - new frontiers in international relations. New York: Longman, 1986.

PAGANOTTI, Ivan. Uma certa libertinagem, muito carnaval e um pouco de pecado - o Brasil dos correspondentes internacionais [Trabalho de Conclusão de Curso]. São Paulo: ECA-USP, 2007.

PINHEIRO, Daniela. "Correspondentes estrangeiros - eles levam um vidão". Revista Veja (27/11/02).

PHILLIPS, Tom, "Slaves' mass grave is grim reminder of Brazil's racist legacy", The Guardian, 30/12/2005.

PRATT, Mary Louise. Os olhos do império - relatos de viagem e transculturação. Bauru: Edusc, 1999.

TALESE, Gay. O reino e o poder - uma história do New York Times. São Paulo: Companhia das Letras, 2000.

WURGAFT, Ramy, "Un mayor despliegue de tropas bloquearía las rutas de la droga", El Mundo, 25/09/2005.

\section{Fontes orais}

Gareth Chetwynd. Correspondente do The Guardian e The Observer. Entrevistas em 11/05/07 e 25/05/07.

Sérgio Barreto Motta. Correspondente do Diário de Notícias de Portugal. Entrevista em 11/05/2007.

\footnotetext{
${ }^{1}$ Este artigo original baseia-se nas pesquisas do Trabalho de Conclusão de Curso de Comunicação Social "Uma certa Libertinagem, muito carnaval e um pouco de pecado - O Brasil dos correspondentes internacionais" (PAGANOTTI, 2007), apresentado ao Departamento de Jornalismo e Editoração da Escola de Comunicações e Artes da Universidade de São Paulo (CJE-ECA-USP) em julho de 2007 ${ }^{2}$ Jornalista freelancer formado pela Universidade de São Paulo, professor de Jornalismo do Colégio Stockler.
} 